\title{
Rancang Bangun Mesin Rol Bending Pipa Besi
}

\author{
Abram Tangkemanda ${ }^{1 *}$, Arthur Halik Rasak ${ }^{2}$, Febriyanto ${ }^{3}$, Fhiral Renaldy ${ }^{4}$ dan Muh. Erfin $^{5}$ \\ 1,2,3,4,5 Jurusan Teknik Mesin, Politeknik Negeri Ujung Pandang, Makassar 90245, Indonesia \\ abramtangkemanda@poliupg.ac.id
}

\begin{abstract}
The process of bending pipes (bending), used to make industrial and household components such as chairs, fences, canopies, and other equipment. It uses pipes as the basic material. The fact shows that demand for those products is getting higher with good quality. The tools for supporting its manufacture also increase by the time. Pipe iron roller bending machine can help for small and medium economic industries because of its affordable cost. For this reason, the research is to design a pipe bending roller machine with a hydraulic jack system using electric motor. The benefits are to facilitate the bending process in the pipe, to minimize cracks in the pipe and to determine the specifications of the material to be bent related to the ability of the bending tool by using a calculation method where the results later as a basis for designin.
\end{abstract}

Keywords: Bending, iron pipe roller bending machine; hydraulic jack system; electric motor power.

\begin{abstract}
Abstrak: Proses penekukan pipa (bending), biasanya banyak sekali dilakukan untuk membuat komponen-komponen industri maupun rumah tangga misalnya membuat kursi, pagar, kanopi, serta perlengkapan lainnya yang memanfaatkan pipa sebagai bahan dasarnya. Hal tersebut diatas, menunjukan bahwa kebutuhan produk semakin lama semakin tinggi dengan kualitas yang baik dan sama halnya dengan peralatan (mesin-mesin), yang semakin lama di tuntut untuk lebih berkembang dan berkembang lagi,sehingga dengan biaya yang terjangkau mesin rol bending besi pipa ini dapat membantu untuk perindustrian ekonomi kecil dan menengah. Untuk itulah maka penelitian dilakukan dengan merancang mesin rol bending pipa dengan sistem hydraulic jack dan menggunakan tenaga motor listrik sehingga mempermudah proses pembendingan pada pipa, lebih meminimalisir terjadi keretakan pada pipa dan Menentukan spesikasi material yang akan dibending terkait dengan kemapuan alat bending dengan menggunakan metode perhitungan dimana hasilnya nanti sebagai dasar untuk merancang.
\end{abstract}

Kata kunci : Bending, Mesin Rol Bending Besi Pipa; Sistem Hydraulic Jack; Tenaga Motor Listrik.

\section{PENDAHULUAN}

Pada masa sekarang ini, semua aktivitas industri dituntut harus cepat, tepat dan sebisa mungkin menggunakan tenaga manusia yang sedikit. Salah satunya adalah proses pengerolan pipa. Pada industri skala Home industry masih banyak didapati alat/mesin pengerol pipa secara manual. Selain membutuhkan waktu yang lama dalam pengoperasiannya, tenaga yang digunakan juga relatif besar. Sebagai solusi dari permasalahan tersebut ialah membuat alat/mesin pengerol pipa yang cepat. Penggunaan motor listrik sangat membantu untuk mempermudah dalam proses pengerolan karena hanya membutuhkan sedikit tenaga dan waktu. Ditambah dengan penggunaan hidrolik jack (dongrak) yang dihubungkan dengan roller penekan sebagai penerus tekanannya. Alat ini juga merupakan inovasi dari alat/mesin rol bending pipa sebelumya dengan membuat desain konstruksinya menjadi praktis dan efektif dalam pengoperasiannya.

Selain untuk mempermudah dan mempercepat dalam pekerjaan, produksi yang dihasilkan juga lebih tepat sehingga lebih efektif dan efesien. Dalam pembuatan sebuah alat/mesin pengerol pipa ini dibutuhkan pemilihan bahan yang tepat, sehingga alat/mesin ini mampu bekerja secara optimal. Di samping itu, dalam pemilihan bahan yang tepat akan dihasilkan alat/mesin yang baik pula dilihat dari segi kekuatan maupun keawetan (lifetime) alat/mesin tersebut.

Sebelumnya mesin rol dengan menggunakan motor listrik sebagai tenaga penggerak pernah dibuat [1] dimana pipa yang dirol hanya satu ukuran dan satu jenis yakni besi berpenampang segi empat dengan ukuran penampang $50 \times 50 \mathrm{~mm}$ dan susah untuk mengganti roller pada alat/mesin tersebut sehingga hanya pipa penampang yang disebutkan diatas yang hanya bisa dirol pada mesin tersebut, 
Sedangkan pengembangan dari judul di atas yang pernah dibuat [2] dimana pipa yang dirol adalah pipa segiempat dengan ukuran $50 \mathrm{~mm}$ x $50 \mathrm{~mm}$ dan Pipa stainless steel dengan ukuran $\emptyset 1$ inci $(25,4$ $\mathrm{mm})$. Mesin ini dapat menghasilkan pipa dengan radius yang lebih kecil dari rancangan sebelumnya. Waktu yang dibutuhkan untuk mengerol pipa sekitar 10 menit dengan panjang pipa $150 \mathrm{~cm}$. Kekurangan dari mesin ini yaitu punch / dies penekannya tidak bisa diganti-ganti sehingga hanya bisa mengerol jenis besi tertentu yaitu pipa segiempat dan pipa bulat yang sesuai dengan ukuran dies / punch penekan yang telah dibuat.

Kemudian pengembangan selanjutnya dibuat [3] dimana spesifikasi yang diroll antara lain jenis baja yang akan dirol adalah baja pejal berbentuk diameter untuk lingkaran roda traktor dengan ukuran Ø0.63 inch ( $16 \mathrm{~mm}$ ) dengan panjang bentangan $2100 \mathrm{~mm}$ dan baja persegi empat dengan ukuran 4 $\mathrm{mm}$ x $1000 \mathrm{~mm}$ dengan ketebalan $25 \mathrm{~mm}$. Kelemahan mesin-mesin rol bending yang pernah ada sebelumnya umumnya terletak pada bagiaan roller penekannya yang masih menggunakan ulir sebagai penerus tekanan, sehingga dalam pengoperasaiannya akan menggunakan banyak tenaga.

Prinsip dasar alat/mesin tersebut ialah pengerjaan dengan cara memberikan tekanan pada bagian tertentu sehingga terjadi deformasi plastis pada bagian yang diberikan tekanan [4].

\section{Dasar-Dasar Rancang Bangun Mesin Pengolah Jagung Untuk Pakan Ternak}

\section{Reducer Gearbox}

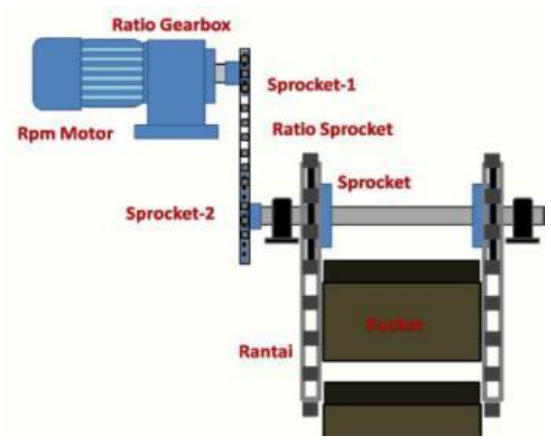

Gambar 1. Sistem transmisi

Kita menginginkan sebuah mesin roll bending dengan putaran $96 \mathrm{Rpm}$, dengan penggerak Motor listrik $2880 \mathrm{Rpm}$, dan Gearbox yang ada memiliki Ratio 1:30, Maka, N2 Gearbox adalah:

$$
\begin{aligned}
& \text { N2 }=\text { N1 }: \text { Ratio (i) } \\
& \text { N2 }=2880: 30 \\
& \text { N2 }=96 \mathrm{Rpm}
\end{aligned}
$$

\section{Daya Motor}

$$
\begin{aligned}
& P=\frac{2 \cdot \pi \cdot n \cdot T}{60} \\
& \text { Keterangan: } \quad \mathrm{P}=\text { daya yang dibutuhkan }(\mathrm{kw}) \\
& \mathrm{T}=\text { Torsi }(\mathrm{Nmm}) \\
& \mathrm{N}=\text { Kecepatan putar }
\end{aligned}
$$

Dimana

$$
T=F \cdot R
$$

Keterangan: $\quad \mathrm{F}=$ Gaya Putar $(\mathrm{N})$

$\mathrm{R}=$ Jarak pisau dari titik pusat $(\mathrm{mm})$

Daya rencana pada motor sebagai berikut: 
99 Abram Tangkemanda, Arthur Halik Rasak, Febriyanto, Fhiral Renaldy, Muh. Erfin. Rancang Bangun Mesin Rol Bending Pipa Besi

$$
\mathrm{Pd}=\mathrm{P} \times \mathrm{fc}
$$

$$
\begin{array}{ll}
\text { Keterangan: } & \mathrm{Pd}=\text { daya rencana } \\
& \mathrm{Fc}=\text { faktor koreksi }
\end{array}
$$

\section{Poros}

a Perhitungan pada poros penggerak

Untuk menentukan perhitungan pada poros penggerak terlebih dahulu dihitung daya perencanaannya [5].

Dimana:

$$
P d=f c . P
$$

$\mathrm{Pd} \quad=$ Daya perencanaan $(\mathrm{kW})$

$\mathrm{Fc} \quad=$ faktor koreksi

$\mathrm{P} \quad=$ Daya masukan $(\mathrm{kW})$

a. Pemilihan bahan poros penggerak

$$
\begin{gathered}
M p=\frac{P d}{\omega}=\frac{60 P d}{2 \pi n} \\
M p=\frac{30}{\pi} \frac{P d}{n}
\end{gathered}
$$

4. Kekuatan Las

$$
A=0.707 \cdot h \cdot l
$$

Dimana: $\quad A \quad=$ Luas Pengelasan $(\mathrm{mm})$

$h \quad=$ Tebal Pengelasan $(\mathrm{mm})$

$l \quad=$ Panjang Pengelasan $(\mathrm{mm})$

Sehingga didapatkan:

$$
\sigma t=\frac{F}{0.707 \cdot h \cdot l}
$$

\section{Analisis penggunaan dongkrak}

Dalam perancangan mesin roll bending pipa ini, hiydraulic jack digunakan untuk memberikan tekanan pada pipa yang akan diroll yang dihubungkan dengan roller utama (Roller Penekan). Sebelum menentukan dongkrak yang akan digunakan, terlebih dahulu harus menentukan jenis pipa yang akan diroll untuk dapat mengetahui besarnya gaya yang digunakan untuk membengkokkan pipa

\section{Kekuatan Baut dan Mur}

$$
\begin{aligned}
\tau g & =0,5 \sigma \mathrm{t} \\
\tau g & =0,5 \frac{\sigma t}{v}
\end{aligned}
$$

Dimana:

$$
\begin{aligned}
& \sigma \mathrm{t}=\text { tegangan tarik } \\
& \mathrm{V}=\text { Faktor keamanan }
\end{aligned}
$$

Pada sambungan baut, tegangan yang sering terjadi adalah tegangan akibat gaya luar yaitu tegangan tarik atau tegangan geser, untuk mengetahui besar tegangan gesernya digunakan persamaan [6]:

$$
\tau g=\frac{4 F}{n \cdot \pi d^{2}}
$$


Keterangan:

$$
\begin{aligned}
\tau_{g} & =\text { Tegangan geser yang terjadi }\left(\mathrm{N} / \mathrm{mm}^{2}\right) \\
\mathrm{F} & =\text { Beban yang diterima }(\mathrm{N}) \\
\mathrm{D} & =\text { Diameter baut }(\mathrm{mm}) \\
\mathrm{N} & =\text { Jumlah baut terpasang }
\end{aligned}
$$

\section{Perhitungan Pada Bantalan}

Gaya gesek pada bantalan[7]:

$$
W=f \cdot P_{0}
$$

Panas yang timbul karena gesekan:

Keterangan:

$$
Q=\frac{\pi \cdot n \cdot f \cdot P_{0} \cdot d_{0}}{427 \cdot 100}
$$
$\mathrm{W}$ = Gaya gesek pada bantalan
$\mathrm{f} \quad=$ koefisien gesek bantalan
$\mathrm{P}_{\mathrm{o}}$ = gaya tekan pada bantalan
$\mathrm{Q}$ = Panas yang timbul karena gesekan

\section{METODE PENELITIAN}

Metode yang digunakan dalam penyelesaian masalah dalam mendesain alatpress tooldalampenelitian ini adalah perancangan, pembuatan, dan pengujian

\section{A. Perancangan}

Dalam perancangan mesin roll bending pipa ini, hiydraulic jack digunakan untuk memberikan tekanan pada pipa yang akan diroll yang dihubungkan dengan roller utama (Roller Penekan). Mesin rol bending pipa ini menggunakan motor listrik 2 HP sebagai sumber penggerak dan ditransmisikan ke kopel yang terhubung dengan reducer kemudian dari reducer akan ditransmisikan ke poros melalui sprocket dan rantai. Ketika sprocket pada poros berputar maka poros pun ikut berputar karena terpasang pasak pada gear dengan poros. Poros inilah yang memutar roller sehingga pipa akan bergerak dari kiri ke kanan ataupun sebaliknya. Roller penekan diturunkan untuk memberi tekanan hingga mendapatkan radius pengeroral yang diinginkan.

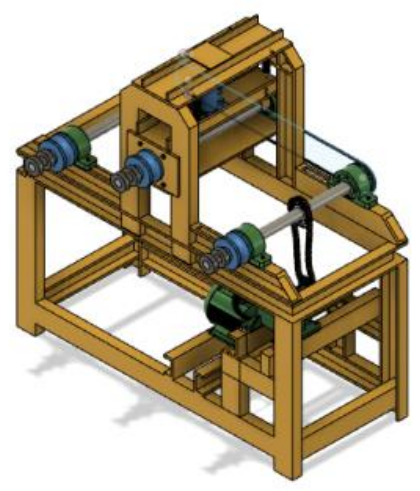

Gambar 2. Rancangan mesin rol bending besi pipa

\section{B. Pembuatan}

Metode selanjutnya setelah proses desain dilakukan, maka proses yaitu proses pembuatan dan pengadaan komponen 
101 Abram Tangkemanda, Arthur Halik Rasak, Febriyanto, Fhiral Renaldy, Muh. Erfin. Rancang Bangun Mesin Rol Bending Pipa Besi

Komponen-komponen mesin rol bending pipa besi terdiri dari :
a. Rangka Utama
b. Rangka Roller Penekan
c. Dies Besi Hollow
d. Poros
e. Dudukan Sprocket
f. Sprocket $14 \mathrm{~T}$
g. Sprocket $36 \mathrm{~T}$
h. Rantai
i. Bantalan/Bearing
j. Motor AC
k. Gearbox/Reducer
1. Per Spring tarik
m. Hydraulic jack kapasitas 2 ton

Setelah komponen-komponen tersebut dibuat, dilanjutkan dengan kegiatan perakitan sehingga diperoleh mesin rol bending pipa besi seperti pada Gambar 3 di bawah ini.
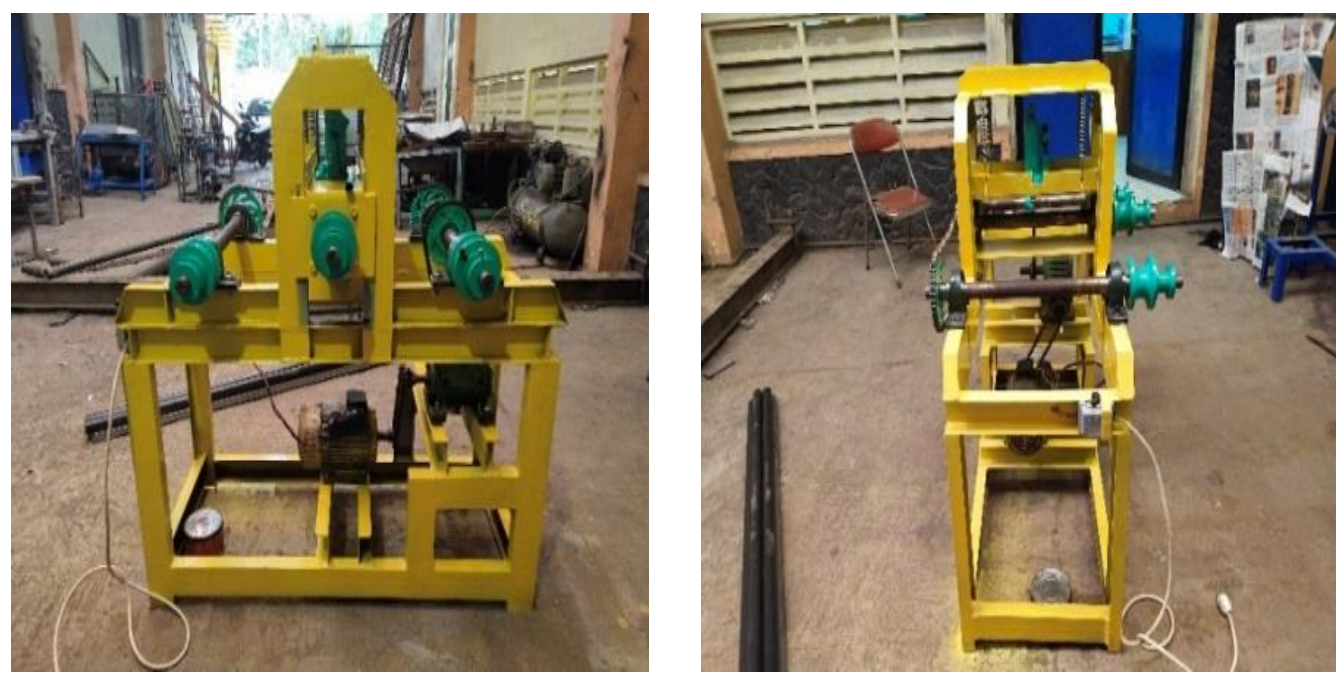

Gambar 3. Mesin rol bending besi pipa

\section{Pengujian}

Pengujian mesin rol bending pipa dilaksakan di bengkel las jurusan teknik mesin politeknik negeri ujung pandang. Sebelum pengoperasian mesin, terlebih dahulu dilakukan proses pengecekan tiap komponen untuk memastikan bahwa mesin telah siap dioperasikan.

Prinsip kerja mesin rol bending pipa adalah dengan meletakkan pipa yang akan dirol di atas roller, kemudian menurunkan roller penekan hingga menyentuh pipa 


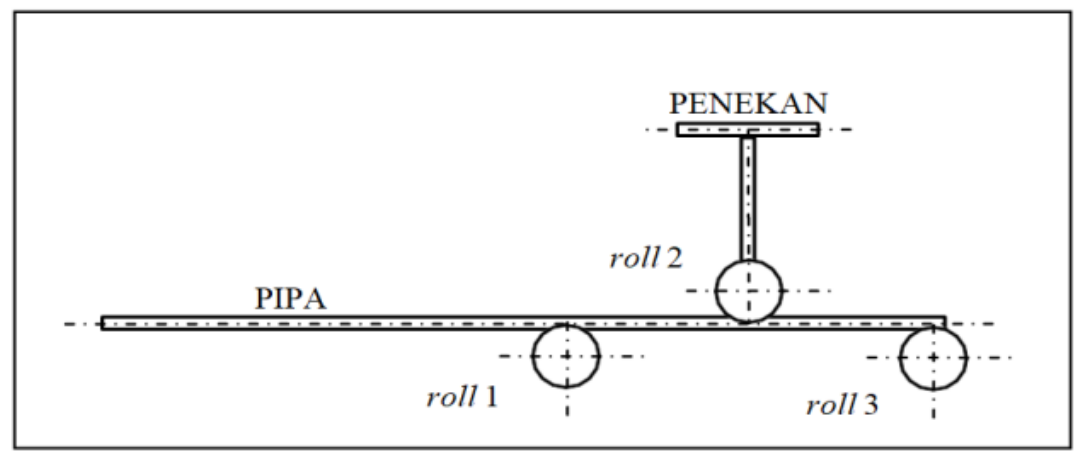

Gambar 4. Prinsip pengujian mesin rol bending pipa

Mesin rol bending besi pipa diuji menggunakan dua jenis benda kerja, yaitu besi pipa dan besi hollow. Pengujian dilakukan untuk mengetahui apakah mesin dapat berfungsi dengan baik.

\section{Perhitungan dan Analisis Data}

Data yang diperoleh melalui pengujian akan diuji secara deskriptif, yaitu memberikan gambaran mengenai produktifitas dan kemudahan dalam melakukan pengerolan besi, kemudian hasil pengujian alat akan dikembangkan lebih lanjut, hingga akan didapatkan hasil yang memiliki efisiensi yang tinggi dan rancangan yang sesuai dengan yang direncanakan.

\section{HASIL DAN PEMBAHASAN}

Hasil yang diperoleh dari kegiatan ini yaitu sebuah mesin rol bending besi pipa. Setelah dilakukan pengujian alat diperoleh hasil berupa dimensi dan kondisi bahan uji hasil pengerolan. Hasilnya seperti tertera pada Tabel 1 
103 Abram Tangkemanda, Arthur Halik Rasak, Febriyanto, Fhiral Renaldy, Muh. Erfin. Rancang Bangun Mesin Rol Bending Pipa Besi

Tabel 1. Hasil Pengujian

\begin{tabular}{|c|c|c|c|c|c|}
\hline \multirow{2}{*}{ No } & \multirow{2}{*}{$\begin{array}{c}\text { Bahan } \\
\text { Uji }\end{array}$} & \multirow{2}{*}{ Ukuran } & \multirow{2}{*}{$\begin{array}{l}\text { Jarak } \\
\text { Tekan }\end{array}$} & \multicolumn{2}{|c|}{ Kondisi Bahan Uji Hasil Pengerolan } \\
\hline & & & & Radius & Keterangan \\
\hline 1 & Pipa & $\begin{array}{l}Q 1 \frac{3}{4} " \times 2000 \\
\mathrm{~mm}\end{array}$ & $50 \mathrm{~mm}$ & $\begin{array}{l}3161 \\
\mathrm{~mm}\end{array}$ & $\begin{array}{l}\text { - Diameter pipa } \\
\text { mengalami perubahan. } \\
\text { (oval) } \\
\text { - Belum ada kerutan pada } \\
\text { pipa }\end{array}$ \\
\hline 2 & Pipa & $\begin{array}{l}Q 1 \frac{3}{4} " \times 2000 \\
\mathrm{~mm}\end{array}$ & $100 \mathrm{~mm}$ & $\begin{array}{c}1376,125 \\
\mathrm{~mm}\end{array}$ & $\begin{array}{l}\text { - Diameter pipa } \\
\text { mengalami perubahan } \\
\text { yang signifikan } \\
\text { - Terdapat bebrapa } \\
\text { kerutan halus maupun } \\
\text { kasar }\end{array}$ \\
\hline 3 & $\begin{array}{c}\text { Besi } \\
\text { hollow }\end{array}$ & $\begin{array}{l}30 \mathrm{~mm} \times 30 \\
\mathrm{~mm} \times 2000 \\
\mathrm{~mm}\end{array}$ & $50 \mathrm{~mm}$ & $\begin{array}{l}3050 \\
\mathrm{~mm}\end{array}$ & $\begin{array}{l}\text { - Terdapat banyak } \\
\text { kerutan } \\
\text { - Terjadi perubahan } \\
\text { ukuran pada besi }\end{array}$ \\
\hline 4 & $\begin{array}{c}\text { Besi } \\
\text { hollow }\end{array}$ & $\begin{array}{l}30 \mathrm{~mm} \times 30 \\
\mathrm{~mm} \times 2000 \\
\mathrm{~mm}\end{array}$ & $100 \mathrm{~mm}$ & $\begin{array}{c}1350,50 \\
\mathrm{~mm}\end{array}$ & $\begin{array}{l}\text { - Kerutan kasar di semua } \\
\text { sisi benda uji } \\
\text { - Terjadi perubahan } \\
\text { ukuran pada besi }\end{array}$ \\
\hline
\end{tabular}

Pengujian mesin rol bending besi pipa ini dilakukan sebanyak 4 kali dengan 2 jenis bahan uji. Putaran mesin yang digunakan adalah $2800 \mathrm{rpm}$ (standar). Adapun untuk menentukan radius hasil pengerolan benda uji menggunakan aplikasi Autodesk Fusion 360.

Pada pengujian awal mesin rol bending besi pipa, bahan uji digunakan ialah besi pipa galvanis ukuran $1 \frac{3}{4} "$ x $2000 \mathrm{~mm}$. Pada pengujiaan ini, roller penekan diturunkan 50mm menggunakan hydraulic jack secara bertahap. Radius pengerolan pada benda uji yaitu $3161 \mathrm{~mm}$. 

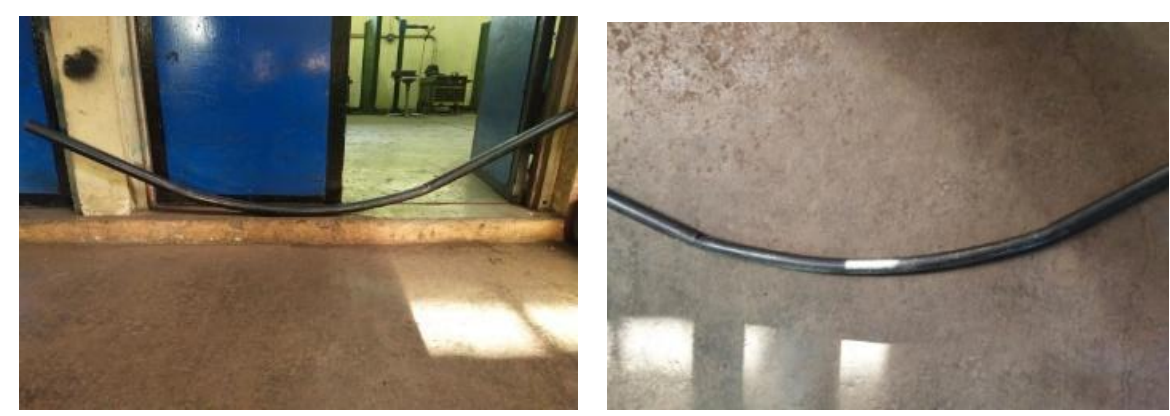

Gambar 5. Hasil pengujian Tahap 1

Pada pengujiaan kedua, dilanjutkan dengan menurunkan roller penekan hingga $100 \mathrm{~mm}$ menggunakan hydauric jack secara bertahap. Bahan uji pada pengujian ini masih menggunakan besi pipa dengan ukuran $Q 1 \frac{3}{4}$ ” x $2000 \mathrm{~mm}$. Radius pengeroral pada benda uji yaitu 1376,125 mm Kondisi benda uji mengalami perubahan diameter yang signifikan dan terdapat banyak kerutan.

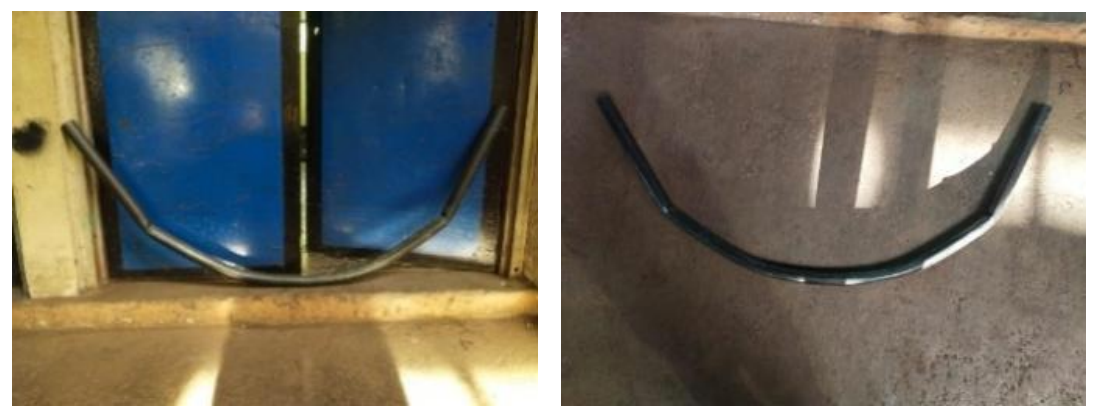

Gambar 6. Hasil pengujian tahap 2

Selanjutnya, pada pengujian tahap ketiga bahan uji diganti dengan besi hollow ukuran 30 $\mathrm{mm}$ x $30 \mathrm{~mm}$ x $2000 \mathrm{~mm}$. Pengerolan ini juga menggunakan dies yang berada paling depan, yaitu dies khusus untuk besi hollow. Pengujian tahap ketiga ini sama seperti pengujian pada tahap pertama, yaitu roller penekan diturunkan secara perlahan menggunakan hydraulic jack hingga 50 $\mathrm{mm}$. Radius pengerolan pada benda uji yaitu sekitar $3050 \mathrm{~mm}$. Berbeda dengan besi pipa, hasil pengerolan dengan bahan uji besi hollow terdapat banyak kerutan yang diakibatkan karena besi hollow memiliki sudut sehingga sangat mustahil untuk menghindari kerutan.
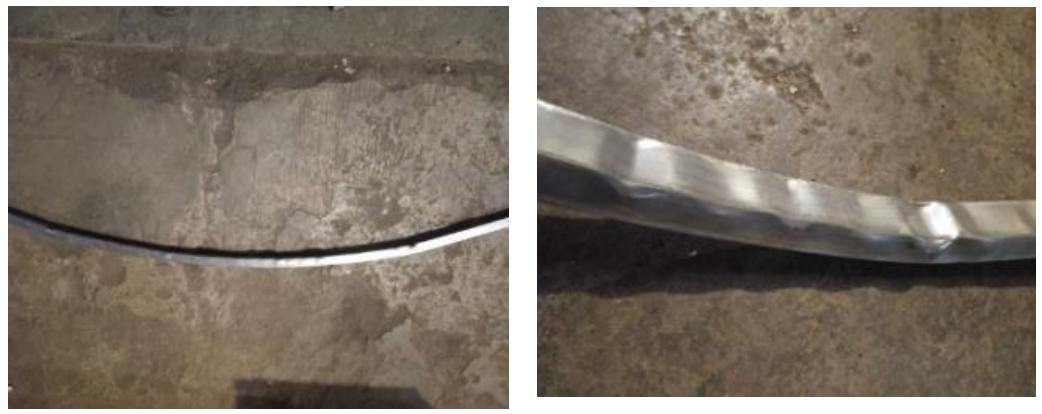

Gambar 7. Hasil Pengujian tahap 3 

Rol Bending Pipa Besi

Pengujian yang terakhir, bahan uji yang digunakan sama seperti pengujian ketiga yaitu besi hollow ukuran $30 \mathrm{~mm}$ x $30 \mathrm{~mm}$ x $2000 \mathrm{~mm}$. Pada pengujian ini roller penekan diturunkan 100 $\mathrm{mm}$. Radius pengeroral bahan uji yaitu sekitar $1350,50 \mathrm{~mm}$ kondisi bahan uji pada pengujian ini terdapatbanyak sekali kerutan kasar yang terdapat di semua sisi bahan uji.
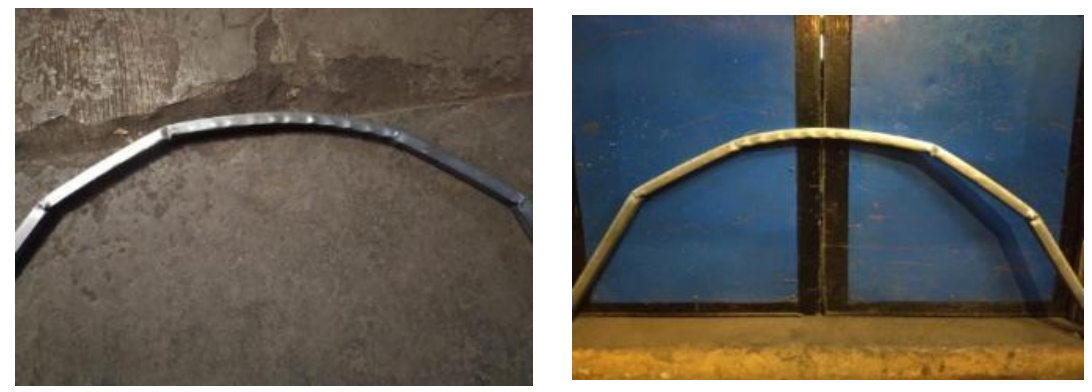

Gambar 8. Hasil Pengujian tahap 4

\section{KESIMPULAN}

Dimensi alat/mesin pengerol pipa secara keseluruhan adalah $1200 \mathrm{~mm}$ x $500 \mathrm{~mm}$ x $1300 \mathrm{~mm}$. Rangka mesin terbuat dari bahan besi UNP $80 \mathrm{~mm}$ x $6000 \mathrm{~mm}$ dengan jenis baja St 42 . Bahan dasar poros menggunakan besi As St 42 dengan ukuran diameter 1,5 inch. Menggunakan hidrolik jack (dongrak) yang dihubungkan dengan roller penekan sebagai penerus tekanannya. Mesin rol ini memiliki 2 punch/dies dengan fungsi yang berbeda dimana dapat mengerol pipa berbentuk lingkaran diameter 1 inch - $1 \frac{3}{4}$ inch dan hollow persegi empat dengan ukuran $30 \mathrm{~mm}$ x $30 \mathrm{~mm}$. Sistem transmisi yang digunakan gear sprocket dan rantai. Gear sprocket yang digunakan ada 4 buah yaitu gear motor 36T 2 buah dan gear 14T 2 buah. Menggunakan daya motor listrik sebesar 2 HP dengan kecepatan $2880 \mathrm{rpm}$. Menggunakan gearbox WPA 070 ratio $1: 30$ untuk mereduksi putaran dan roda gigi $1: 2$ dengan kecepatan akhir $48 \mathrm{rpm}$.

\section{DAFTAR PUSTAKA}

[1] Warsih, Eko, dkk. 2007. Rancang Bangun Mesin Rol Pipa Segi Empat: Politeknik Negeri Ujung Pandang.

[2] Ambari, Muarif, dkk. 2014. Pengembangan Mesin Rol Pipa Sistem Vertikal: Politeknik Negeri Ujung Pandang

[3] Ahmad, dkk. 2016. Pengembangan Desain Mesin Rol Besi Pejal Bulat Dan Persegi: Politeknik Negeri Ujung Pandang.

[4] Mustaqim, Ahmad. 2012. Perancangan Alat Pengerol Pipa. Yogyakarta : Universitas Negeri Yogyakarta. 